\title{
DO VERSO AO BERRO: VOZES DE RESISTÊNCIAS FRENTE AO PROJETO “CIVILIZATÓRIO BRASILEIRO” NOS CAMPOS DA LITERATURA E DA MÚSICA POPULAR
}

\author{
Filipe da Silva Moreira ${ }^{1}$ \\ Pedro Teixeira Castilho ${ }^{2}$
}

\begin{abstract}
Resumo: O presente artigo tem por objetivo analisar, na formação cultural brasileira, a linguagem de resistência em épocas distintas, a partir de uma perspectiva decolonial (FANON, 2020), considerando o projeto civilizatório de nação por que passou o Brasil do início do século XIX. Trata-se, assim, de perceber as vozes de resistências que soaram, no início da República, em defesa dos socialmente excluídos com Luiz Gama, na literatura, e com Alberto Nepomuceno, na formação da canção brasileira, e contemporaneamente as expressões literárias de Conceição Evaristo, por meio do conto "A gente combinamos de não morrer", e o estilo musical do Rap no cenário sociocultural brasileiro.
\end{abstract}

Palavras-chave: linguagem; resistência; projeto civilizatório.

Abstract: The present work aims to analyze, in the Brazilian cultural formation, the language of resistance at different eras, from a decolonial perspective (FANON, 2020), considering the nation civilization project which Brazil went through at the beginning of the XIX century. Therefore, it is about perceiving the voices of resistance that sounded, at the beginning of the Republic, in defense of the excluded from the society, with Luiz Gama, in literature, and with Alberto Nepomuceno, in the formation of Brazilian song, and contemporaneously the literary expressions of Conceição Evaristo, through the short story "A gente combinamos de não morrer", and the musical style of Rap in the Brazilian sociocultural scenario.

Keywords: language; resistance; civilization project.

1 Professor de Literatura e Técnico em Assuntos Educacionais do Instituto Federal de Minas Gerais - Campus Ibirité. Mestrando em Educação e Docência pela FAE/UFMG. E-mail: filipe.moreira@ifmg.edu.br

2 Professor da Faculdade de Educação UFMG. Doutorado em Teoria Psicanalítica (UFRJ) e Pós-Doutorado em Psicologia Clínica (USP). E-mail: contatocastilho@gmail.com 


\section{Introdução}

Houve um momento na história da humanidade em que a cultura mantinha laços muito mais estreitos e determinantes na formação de uma nação, e, nestes períodos, desde o início do século XIX, por uma hipótese filológica, a literatura, a língua e a cultura eram consideradas pilares para a construção unificada de uma nação, sendo a literatura o principal meio para a aquisição de conhecimento de uma cultura em sua totalidade (COMPGNON, 2012). Portanto, no século XIX, a leitura literária responsabilizava-se pela formação cultural de uma civilização, não havendo outra representação cultural capaz de transmitir os conhecimentos humanistas - éticos e morais - àqueles que se formavam. A literatura deleitava e instruía. Pelo seu caráter ficcional - mimèses - à literatura era atribuído um poder de instrução moral, no qual se acreditava que a ficção, a quimera, a narrativa educavam moralmente o indivíduo (COMPAGNON, 2012).

Entretanto, ao formar o indivíduo, acreditava-se que a literatura poderia formar também uma sociedade. Mesmo Aristóteles, em A Arte Poética, obra que inaugura o conceito de mimèses, considera que a catharsis provocada pela representação resulta em uma melhora tanto da vida privada quanto da vida pública.

Desse modo, este papel desempenhado pela literatura tomou, no século XIX, proporções ainda maiores na história. A literatura não só se tornou responsável pela formação moral do indivíduo, como também se acreditava ser ela capaz de, no final do século XIX e no início do século XX, proporcionar uma formação moral comum, com finalidades políticas, responsável por instaurar um ideal ético e estético que contribuiria para a paz social (COMPAGNON, 2012). A literatura influenciou a noção de belo e de sublime trazendo no seu bojo um ideal desencarnado de qualquer ideal que contestava o ideal iluminista. A respeito desta crença, Culler (1999) descreve relatos da Inglaterra do século XIX e da fundamental participação da literatura na formação dessa sociedade por diversos aspectos:

$\mathrm{Na}$ Inglaterra do século XIX, a literatura surgiu como uma ideia extremamente importante, um tipo especial de escrita encarregada de diversas funções. Transformada em matéria de instrução nas colônias do Império Britânico, ela encarregou-se de dar aos nativos uma apreciação da grandeza da Inglaterra e de envolvê-los como participantes agradecidos num empreendimento civilizador histórico. No plano doméstico, ela podia se contrapor ao egoísmo e materialismo fomentados pela nova economia capitalista, oferecendo às classes médias e aos aristocratas valores alternativos e dando aos trabalhadores uma baliza na cultura que, materialmente, os relegava a uma posição subordinada. Ela iria ao mesmo tempo ensinar apreciação desinteressada, proporcionar um senso de grandeza nacional, criar um sentimento de camaradagem entre as classes e, em última análise, funcionar como um substituto da religião, que parecia não mais ser capaz de manter a sociedade unida. (CULLER, 1999, p. 42).

A função nacional denominada por Culler, no que se refere à literatura, diz respeito à universalização de valores que a literatura pode provocar em uma nação, transformando os 
já vigentes, oferecendo soluções para problemas éticos e morais enfrentados pela sociedade e formando a personalidade dos indivíduos. Desse modo, é evidente que a literatura nos séculos passados ocupava posição central na formação cultural-humanística de cada indivíduo e até de uma sociedade, sendo imputada à arte literária a responsabilidade da formação humana do sujeito.

No Brasil, porém, não foi diferente. Ainda no século XIX, em 1838, com a instauração do Instituto Histórico e Geográfico brasileiro, constituído por um elo entre Estado, homens das letras e intelectuais da época, propõe-se a implantação de um projeto civilizador capaz de circunscrever a origem da nacionalidade brasileira, por meio da historiografia e da arte literária escrita por brasileiros. O objetivo era semelhante à função nacional que a literatura cumpriu na Inglaterra do séc. XIX. Porém, na tentativa de traçar a gênese da brasilidade e, com isso, formar a consciência de uma nação, o projeto civilizatório relegou os índios e os negros a raças inferiores, excluindo-os da construção nacional. O ideal literário no Brasil tinha como bússola um projeto colonizador que pretendia anular e invisibilizar as expressões culturais e os modos de vida que não se apresentavam dentro da perspectiva iluminista. Esta marca da tradição de europeizar a cultura brasileira foi registrada em vários âmbitos. Aqui é importante lembrar do projeto de embranquecimento da raça feito no início do século XX, cujo objetivo era incentivar a imigracao europeia para o Brasil.

Em tempo, é preciso ressaltar que o índio, embora caricato, foi mencionado nas produções da época e, por influência à considerações estrangeiras em relação à literatura brasileira produzida na época, ganhou status de símbolo nacional. Conforme explicita Cristina Betili Ribeiro (2005):

A admissão do índio como símbolo nacional representa também uma resposta a considerações estrangeiras como as de Ferdinand Denis e Almeida Garrett, a respeito de nossa literatura. Primeiro estudioso a publicar um Resumo da história literária do Brasil (1826), independente da historiografia portuguesa, Denis sugere a necessidade de se explorar a cor local e o índio na produção literária nacional. Garrett, que tivera contato direto com a geração de românticos da revista Niterói, em Paris, aponta a conveniência de os literatos brasileiros libertarem-se da educação européia e voltarem-se, com originalidade, especialmente para a natureza tropical. A maior semelhança entre as posições que adotam é a recomendação de se buscar, nas exuberâncias brasileiras, os elementos compensatórios para o atraso da jovem nação. (RIBEIRO, 2005, p. 3)

O negro, contudo, na condição de escravo, era bestializado. Prova disso é justamente a primeira fase do Romantismo literário brasileiro em que a figura do negro era silenciada e longe de ocupar um lugar em destaque nos romances da época. Assim, na construção nacional, os índios, expropriados, e, destacadamente neste artigo, os negros, escravizados, tiveram silenciadas, nas narrativas oficiais do país, sua cultura, história e fundamental contribuição para a formação cultural brasileira.

Neste ínterim, a formação da literatura brasileira, como projeto de constituição de uma nação, mostra-se, neste instante da história, elitista, burguesa e segregatória. Não se 
considerava, pois, no Brasil, diferentemente do que se propôs na Europa, a participação do povo como constituinte de uma nação, ainda que os valores burgueses no velho mundo estivem em evidência. Somente nos anos 70 oitocentistas que os intelectuais manifestaram a preocupação de se incluir a cultura popular como elemento capaz de representar a nação, assim, os estudos desses intelectuais, baseados ainda no Romantismo alemão, traz à tona a sabedoria popular, uma acepção de "espontaneidade ingênua", o que poderia se julgar como "alma nacional” (RIBEIRO, 2005, p. 4). A Escola de Recife, tendo Sílvio Romero como um de seus mais famosos expoentes, nasce a partir dessas discussões sobre o folclore brasileiro.

Ademais, o projeto civilizatório implantado pela elite imperial do início do século XIX no Brasil procurava, também no campo musical, semear a imagem de uma civilização europeia transplantada para a América tropical e, como ação dessa missão história de formar uma nação, inaugura-se, em 1844, o primeiro Conservatório de Música do país. $\mathrm{Na}$ verdade, tanto o Instituto Histórico e Geográfico brasileiro quanto o Conservatório de Música fazem parte de um grupo de instituições, desta época, instauradas com o intuito de encaminhar o país para um fluxo civilizatório europeu, buscando, para todos os brasileiros, um "padrão civilizatório" que pudesse se tornar referência.

Nestes espaços construídos, a propósito de "instruir e deleitar" e de fazer com que essas artes, literárias e musicais, tornassem-se basilares para a formação moral de um povo com a pretensão de educar uma sociedade a partir de uma ordem cortesã, estimuladora dos "bons costumes", os conservatórios de música também utilizavam o discurso da moralidade como base da arte, a partir de uma perspectiva eurocêntrica. A respeito deste aspecto da formação cultural brasileira, Augusto ressalta que: "O discurso da moralidade como base da arte, ou da arte como possuidora de uma essência moral, refletia diretamente os anseios de uma sociedade que buscava sobremaneira distinguir-se como culta e, portanto, detentora dos quesitos básicos a ser recebida no âmbito das nações civilizadas." (AUGUSTO, 2010, p. 70)

Entretanto, a cultura popular, do ponto de vista da História, é sempre abordada por quem não pertence às camadas populares, portanto, é uma criação burguesa da cultura erudita. Desse modo, Chartier (1995) afirma que "os debates em torno da própria definição de cultura popular foram (e são) travados a propósito de um conceito que quer delimitar, caracterizar e nomear práticas que nunca são designadas pelos seus atores como pertencendo à 'cultura popular'” (CHARTIER, 1995, p 179). Assim, na realidade brasileira, o povo também não se fez, como sinalizado na consideração do historiador, parte integrante do grupo responsável por registrar a história e a literatura nacional. Contudo, tanto nos tempos do projeto civilizatório quanto contemporaneamente é possível distinguir as vozes decoloniais soarem no contra fluxo europeu e serem reconhecidas como vozes de resistência à cultura hegemônica.

\section{A linguagem engajada nos versos de Luiz Gama e o nascimento da canção brasileira em Alberto Nepomuceno}

Ainda nos tempos do império, é possível perceber que há, mesmo com a inclinação eurocêntrica incitada pelas instituições advindas do projeto civilizatório, nos campos das 
artes literárias e das musicas, produções destoantes dos valores cívicos e morais da época. Luiz Gama, na literatura, e Alberto Nepomuceno, na música de câmara, são, nesse sentido, expoentes dessa arte de resistência capaz de, por meio de suas obras, abarcar a participação dos excluídos do pacto do poder - os negros - e suas contribuições para a formação da cultura brasileira.

Luiz Gama, negro, advogado, escritor e intelectual, nascido livre 1830 no estado da Bahia, torna-se escravo ainda criança, vendido pelo próprio pai a fim de suprir dívidas. Aos 17 anos, Luiz Gama consegue comprovar sua condição de homem livre ao seu senhor e, liberto, forma-se em Direito e se torna advogado das causas dos negros em situação de escravidão. Seu único livro publicado é Primeiras Trovas Burlescas de Getulino, tendo sua primeira edição publicada em 1859, em São Paulo. Cidade em que o poeta morre em 1882.

Esta é uma obra de cunho satírico nos âmbitos sociais e políticos. Pensar Luiz Gama como homem negro, escravo liberto, porém letrado e participante da sociedade urbana de São Paulo, no período de uma efervescência a respeito da constituição de uma identidade nacional, pautada nos valores europeus, é pensar em resistência só pelo lugar social em que ele ocupava. Contudo, sua obra parece trazer elementos de resistência como forma imanente da escrita a partir da ridicularização do padrão civilizatório. A estratégia de adotar em sua escrita de poesia o sarcasmos e a sátira social e política demonstra a potência e a sutileza do autor em confrontar a mentalidade burguesa vigente. Assim, é, conforme Alfredo Bosi, relevante a intersecção de poesia e resistência nas seguintes modalidades:

a resistência da sátira e da paródia, sem dúvida as suas formas mais ostensivas; a resistência profunda, às vezes difícil de sondar, da poesia mítica; a resistência interiorizada da lírica, que entrança os fios da memória com os da imaginação; enfim, a resistência que se faz projeto ou utopia no poema voltado para a dimensão do futuro. (BOSI, 1996, p. 23)

Desse modo, pode considerar que, no campo das resistências, a obra poética de Luiz Gama é atravessada pele sátira social, pela lírica ao centralizar a representação da mãe e da afirmação de sua matriz africana e, talvez, em uma análise mais aprofundada, pela utopia. Entretanto, este artigo pretende destacar, de modo geral, sem propor uma análise minuciosa, o uso da linguagem na obra publicada de Luiz Gama. A linguagem, portanto, segundo FANON (2020), é um ponto chave na relação colonizado e colonizador:

Todo povo colonizado - isto é, todo povo em cujo seio se originou um complexo de inferioridade em decorrência do sepultamento da originalidade cultural local - se vê confrontado com a linguagem da nação civilizadora, quer dizer, da cultura metropolitana. O colonizado tanto mais se evadirá da própria selva quanto mais adotar os valores culturais da metrópole. Tão mais branco será quanto mais rejeitar sua escuridão, sua selva. (FANON, 2020, p. 32)

É, pois, exatamente este o confronto travado por Luiz Gama a partir de sua obra. Os poemas nela retratados travam um combate com a cultura vigente quando, por meio da 
linguagem, carregada de elementos africanos, propõem discutir temas subjacentes a sua identidade racial que retratam o lugar do negro na sociedade que se formava. A resistência acontece como tema da narrativa e como elemento intrínseco à escrita. No que tange ao tema, Gama dá protagonismo ao negro, quando, no início do romantismo, a elite intelectual reduzia-se apenas em retratar, ainda que de maneira muito deturpada, o índio como elemento formador da cultura nacional. Além disso, Gama, conforme analisa, de maneira muito detalhada, Eduardo Antonio Estevam Santos (2015), apresenta em seu texto uma linguagem engajada com as questões de raça até então silenciadas no contexto cultural brasileiro, sobretudo na proposta de construção de uma História e Literatura nacionais à época.

Luiz Gama recupera aspectos da cultura afro-brasileira por meio de memórias, rastros, resíduos, presentes na linguagem, no cotidiano. Primeiras Trovas Burlescas de Getulino apresenta um léxico híbrido, no qual estão presentes palavras do cotidiano popular e fortes referências à África: marimba, urucungo, candimba, azeviche, musa da Guiné. Faz um jogo entre as línguas, demonstrando a hibridez na formação linguística brasileira. Gama pensou e escreveu entre as línguas. Este ato é conceituado por Walter Mignolo como linguajamento, uma língua que não se resume a regras sintáticas, semânticas e fonéticas, mas que "são estratégias para orientar e manipular os domínios sociais de interação107”. Em resumo, o linguajamento é uma prática cultural e uma luta pelo poder108 no que tange à hierarquização das línguas. (SANTOS, 2015, p. 745)

Assim como Luiz Gama, a estética da resistência se prolonga à formação musical que se propunha no projeto civilizatório brasileiro. Naturalmente, com a criação dos conservatórios de músicas, escolas de belas artes dentre outras instituições artístico-culturais, a influência europeia na constituição do que se gostaria de chamar música brasileira era evidente e o surgimento de uma música feita sob fortes influências da concepção erudita ganha destaque nacional. Carlos Gomes (1836-1896), autor da ópera O Guarani, com primeira apresentação datada em 1870, inspirada na obra de José de Alencar é um bom exemplo de produção à época. Assim, instaurava-se pouco a pouco no Brasil a difusão da música erudita como a socialmente aceitável.

Contudo, no âmbito da música popular, já eram socialmente e manifestas e difundidas as práticas dos batuques dos negros, Umbigadas, Jongos e outras mais, ainda que essas manifestações acontecessem clandestinamente, pois toda cultura negra não só foi silenciada como também perseguida, sendo o Estado capaz de tornar, por exemplo, a prática da capoeira uma infração legal. Ademais, mesmo que fossem práticas proibidas pela lei vigente, foram, nos quilombos, pontos de resistência, que se manteve a tradição e viva a cultura negra, fundamental para formação desta nação chamada Brasil. Por conseguinte, essas manifestações de cultura espontânea começaram a fazer parte das construções, embora pouco engajadas inicialmente, dos compositores tais como o já citado Carlos Gomes, Heitor Villa-Lobos (1887-1959) e, como principal elemento de análise neste artigo, Alberto Nepomuceno (1864-1920).

Alberto Nepomuceno é cearense e foi músico de formação erudita e carreira inter- 
nacional. Aos 17 anos, aproximadamente, Nepomuceno passa a se relacionar com alunos e professores da Faculdade de Direito vinculada à Escola de Recife. Essa aproximação de Nepomuceno aos estudos do folclore brasileiro, por meio da Escola de Recife, pode antecipar a interpretação dos rumos de sua obra, principalmente na valorização da música brasileira. Nepomuceno foi também regente, na Alemanha, da Orquestra Sinfônica de Berlim, em sua segunda ida ao país após 1890.

Nesse sentido, a contribuição da obra de Nepomuceno neste artigo se destina a análise, mais uma vez, do uso da linguagem. Nepomuceno é o mais expressivo compositor brasileiro a nacionalizar a música, utilizando textos escritos em língua portuguesa em suas canções, e, nesse viés, flexiona as tradições musicais europeias, criando, assim, o primeiro cancioneiro erudito brasileiro. Embora a música popular ainda não tivesse seu espaço conquistado no cenário cultural oficial brasileiro, seus elementos e a língua pátria eram introduzidos pelas canções de Alberto Nepomuceno.

As composições de Nepomuceno são fundamentadas na prática da junção de poesia e melodia recorrente no Ocidente desde a Grécia Antiga, quando as épicas eram catadas por um solista, e as líricas pelo coro. Porém, é no início do século XIX que se expande, na Alemanha e na Áustria, um fenômeno chamado Lied romântico. O chamado Lied romântico se estabelece na Europa com o ressurgimento da poesia alemã conjugada a outros gêneros vocais, como a cantata e a ópera, e com as canções folclóricas e tradicionais, nestas últimas, reduzidas à voz e piano. Nepomuceno, à luz desta prática, estabelece a criação da canção brasileira e, com isso, ganha a qualificação de "Schubert brasileiro". A valorização do idioma local, do batuque, da capoeira, da cultura popular e espontânea de origem africana em sua obra ainda que basilarmente erudita cria novos espaços de resistência de um povo silenciado ante aos anseios nacionais de legado e formação cultural eurocêntricos.

Dois vetores norteiam a criação de uma música brasileira a que se propôs Nepomuceno: um é a língua e sua musicalidade intrínseca, sem dúvida o mais importante e o que determinou que a canção fosse seu laboratório, em que a música europeia seria flexionada pela poesia nacional, abrasileirando-se o processo. $\mathrm{O}$ outro é a ideia de 'raça', em que o elemento nativo, índio ou negro, sofre um processo de branqueamento ao ser adaptado à música da cultura dominante. As peças que seguem este aspecto, ou seja, que incorporam elementos folclórico, são as que os modernistas identificam como 'nacionalistas', em que o elemento nacional é explícito. (PIGNATARI, 2015, p. 45)

Por fim, os movimentos de Nepomuceno na composição de uma obra erudita com elementos da cultura popular marginalizada permitem que, mesmo que sutilmente, a voz do povo fosse, de alguma maneira, inserida e ouvida pela burguesia dominante. Assim, sua contribuição para manter viva a tradição do povo negro, escravizado e marginalizado perante a sociedade brasileira, na primeira fase do período romântico brasileiro, considerando os ambientes elitistas a que sua arte tinha acesso, prenuncia a força com que o povo negro e marginalizado contemporaneamente imprime, através de sua arte, as suas lutas atuais. Se, nos tempo do império, as vozes de resistências eram, quando não silenciadas, sutis. 
Hoje, essas vozes são berros, gritos por justiça e dedo na ferida do preconceito racial e da desigualdade social que dividem a sociedade brasileira.

\section{RAP nacional, Conceição Evaristo e os gritos do morro}

A literatura brasileira e a música popular fizeram um longo caminho até o nascimento e constituição do Rap nacional e do surgimento obra de Conceição Evaristo, no século XXI. Este artigo faz um salto na história, na tentativa de aproximar a luta por reconhecimento de uma cultura popular negra e marginalizada em dois momentos distintos da história nacional. Nesse sentido, as proposições de Luz Gama e Alberto Nepomuceno na construção de uma linguagem decolonial tornam, nas obras de Evaristo e no surgimento do Rap nacional, ecos de uma voz agora potencializada pela condição social desfavorável e pela transformação da relação do individuo com a cultura, considerando o advento da hipermodernidade.

Neste cenário de mudanças, a própria concepção de cultura transformou-se junto com as transformações sociais. A hipermodernidade (LIPOVETSKY; SERROY, 2011) apresenta outra forma de regime cultural, diferente da anterior vivenciada em que a cultura era a responsável pela transmissão dos valores sociais, tendo como principal meio a literatura.

Transformações que permitem falar de um novo regime de cultura, o da hipermodernidade, em que os sistemas e valores tradicionais que perduraram no período anterior não são mais estruturantes, em que já não são verdadeiramente operantes senão os próprios princípios da modernidade. Além da revitalização das identidades coletivas herdadas do passado, é a hipermodernização do mundo que avança, remodelado que ele está pelas lógicas do individualismo e do consumismo. (LIPOVETSKY; SERROY, 2011, p. 13)

É, portanto, sobre as balizas dessa hipermodernidade e da impossibilidade, além do fracasso evidente, de se instaurar no Brasil o projeto civilizatório vislumbrado no século XIX que surgem, nos anos 90 do século XX, em meio a uma política econômica nacional neoliberal responsável por agravar as desigualdades sociais ao longo da década, artistas impulsionados por movimentos sociais capazes de trazer em suas obras a realidade silenciada e escondida no campo da cultura oficial. É neste cenário político-social que o Rap nacional e a literatura marginal-periférica ganha espaço nas periferias do país.

No campo da literatura, o engajamento acerca da escrita de uma literatura capaz de retratar a periferia com olhar periférico faz com que as produções dobrem em pouco tempo e seu consumo cresça, resultando mais engajamento nesta equação. De acordo com Érika do Nascimento, o que mais impressionou em sua pesquisa foi:

a ampliação de obras e práticas associadas à literatura marginal-periférica que agregou ao movimento outras experiências discursivas, assim como de produção, circulação e consumo cultural. Só para citar um exemplo (e correndo o risco de ser bastante arbitrária), em 2005 havia 17 livros publicados, mas até o final de 2010 era possível contabilizar pelo menos 72 obras de escritores da periferia associados à ideia de literatura marginal-periférica. (NASCIMENTO, 2011, p. 103) 
Assim, a literatura periférica-marginal foi ganhando espaço e, atualmente, já adentra ambientes fora da periferia. A escrita de Conceição Evaristo, brasileira, de origem periféri$\mathrm{ca}$, apresenta um obra em que as mazelas sociais assaltam o leitor de modo a berrar em seus ouvidos "mãos ao alto", numa rendição cinematográfica. A plasticidade das imagens que em sua obra é possível cooptar, desenha uma realidade crua e cruel da sociedade que vive à margem. Neste artigo, é destacado o conto "A gente combinamos de não morrer", presente na obra Olhos D’água, publicada em 2016.

A linguagem é o principal e o mais relevante aspecto a ser comentado. A análise literária proposta não pretende ser minuciosa, mas capaz de retratar, ainda que brevemente, o modo como a escrita denuncia uma tensão social entre o indivíduo e a sociedade em que está inserido. O conto é narrado por uma personagem feminina que, em uma narrativa acelerada de uma dicção próxima ao estilo do canto Rap nacional, ganha ritmo e é capaz de surpreender. Assim como no Rap, o uso da língua é informal e cria, de acordo com o andamento musical, neologismos: "É como se o medo fosse uma coragem ao contrário. Medo, coragem, medo, coragemedo, coragemedo de dor e pânico" (EVARISTO, 2016, p. 100).

O cenário é impactante e móvel, ora é retratado o morro e personagens trocando tiros, ora é uma mãe acalentando o filho e, nessa toada, revelam-se temas como a fome, violência, lei do tráfico, aborto e culpa católica e uma vida acelerada e tanto precária quanto efêmera.

A abordagem desse conto, assim como a obra da escritora, é de uma força narrativa capaz de discutir o lugar marginalizado do negro, pobre, mulher, mulher preta escancarando uma realidade que ultrapassa a representação literária mimética, mas, conforme Alfredo Bosi, enquanto ação de resistência como forma imanente de escrita, apresenta um ponto de vista único e particular orientado por uma estilização da linguagem com a crueza das ruas.

Chega um momento em que a tensão eu/mundo se exprime mediante uma perspectiva crítica, imanente à escrita, o que torna o romance não mais uma variante literária da rotina social, mas o seu avesso; logo, o oposto do discurso ideológico do homem médio. O romancista "imitaria" a vida, sim, mas qual vida? Aquela cujo sentido dramático escapa a homens e mulheres entorpecidos ou automatizados por seus hábitos cotidianos. A vida como objeto de busca e construção, e não a vida como encadeamento de tempos vazios e inertes. Caso essa pobre vida-morte deva ser tematizada, ela aparecerá como tal, degradada, sem a aura positiva com que as palavras "realismo" e "realidade" são usadas nos discursos que fazem a apologia conformista da "vida como ela é"... A escrita de resistência, a narrativa atravessada pela tensão crítica, mostra, sem retórica nem alarde ideológico, que essa "vida como ela é" é. quase sempre, o ramerrão de um mecanismo alienante, precisamente o contrário da vida plena e digna de ser vivida. (BOSI, 1996, p. 23)

Para a geração contemporânea de escritores de literatura de resistência, marginal-periférica, já não é mais uma escolha a linguagem metaforizada ou o uso de um "eufemismo social", o compromisso deles é com verdade, ainda que ficcionalizada. Contudo, é preciso dizer que, ao contrário do que Bosi afirma, há sim nesta literatura, produzida contemporaneamente, inclinação ideológica por um país mais equânime socialmente. 
No cenário musical, o estilo Rap, que embora seja uma apropriação cultural brasileira, soube demonstrar originalidade na construção musical e temática do estilo, sobretudo nos grupos que tiveram projeção nacional nos anos 90. No Brasil, o Rap Ideológico - "caracterizado por letras didáticas que pregam a paz nos guetos, almejando um futuro distante do universo das drogas e da violência" (NATHANAILIDIS, 2011, p. 3) - dominou a cena artística nesta época e foi, assim com é ainda atualmente, instrumento de denúncia das mazelas sociais, assim como responsável pela formação humanística, principalmente, da parcela marginalizada da população. Com temas raciais, o Rap também é responsável por reabrir a discussão acerca do mito da democracia racial brasileira que pairava no Brasil.

Um dos maiores expoentes desse Rap nacional é, sem dúvida, o grupo Racionais MCs, formado no fim dos anos 80, na periferia de São Paulo. Em 1997, é lançado o álbum que, atualmente, é reconhecido pela crítica musical como "a Bíblia do rap", intitulado Sobrevivendo no inferno. Este álbum tornou-se livro em 2018 somente com o registro de suas letras.

O álbum em questão é elogiável não somente pelo conteúdo expressado como um grito do povo marginalizado, excluído e assassinado nas periferias brasileiras, mas pelo modo como esse "grito dos excluídos" acontece. O fato de ser conhecido como a "Bíblia do Rap" não é por acaso, as referências do álbum com o livro sagrado são muitas. A começar pelo título - Sobrevivendo no inferno - e a composição da capa, formada por uma cruz e letras góticas. A primeira canção chama-se "Jorge da Capadócia" e faz referências claras às religiões de matrizes africanas. A segunda canção chama-se "Gêneses" e é uma releitura do texto bíblico feita de forma recitada. E essa canção, em específico, propõe ao ouvinte/leitor o direcionamento temático do disco.

Deus fez o mar, as árvore, as criança, o amor. O homem me deu a favela, o crack, a trairagem, as arma, as bebida, as puta.

Eu?! Eu tenho uma Bíblia velha, uma pistola automática e um sentimento de revolta

Eu tô tentando sobreviver no inferno. (RACIONAIS MCs, 1997)

Não é objetivo deste artigo fazer uma análise pormenorizada da obra, mas apresentar, por essa obra exemplificada, a força do Rap Nacional no debate social instaurado na década de 90 até a atualidade. É por meio de uma estratégia de combate que o Rap nacional aponta o dedo na "cara" da sociedade e denúncia suas perversões.

Ambas as artes, literárias e musicais, portanto, utilizam como linguagem o confronto para se estabelecerem socialmente. E, embora as análises feitas até aqui neste artigo sobre as obras de Nepomuceno e Gama apontam para uma linguagem de aguerrida socialmente, mas ainda apresentada conforme o "padrão civilizatório", tanto a literatura marginal-periférica quanto o Rap são continuações de uma resistência que começa no cerne da discussão da constituição de uma identidade nacional.

As referências ao início do século já evidenciam como, por meio de muitos mecanismos, se tentou segregar e silenciar as populações negras e suas manifesta- 
ções: como o samba, o candomblé, a umbanda e a capoeira. Essas manifestações, porém, possuem um histórico de resistência, se metamorfoseiam e sobrevivem. Esse tipo de rap a que nos referimos, por exemplo, com seu ethos discursivo marcado pelo confronto, é hoje a ponta de um movimento que tem origens antigas. (NASCIMENTO, 2019, p. 84)

\section{Conclusão}

Este artigo pretendeu realizar dois recortes históricos, de momentos distintos do Brasil, para evidenciar as narrativas de resistências nos campos da literatura e da música popular, assim como suas diferentes abordagens sobre o tema. Esse movimento de resistência é um movimento decolonial que se acentua na comparação dos dois períodos históricos analisados. Em ambos os períodos, por mais que, em determinados momentos da história, as narrativas oficiais se negassem a incluir a cultura negra, o negro foi protagonista: tanto em Gama e Nepomuceno quanto na constituição do Rap nacional e na conto e obra de Conceição Evaristo.

\section{Referências Bibliográficas}

AUGUSTO, Antônio. A civilização como missão: o Conservatório de Música no Império do Brasil. Revista Brasileira de Música: Programa de Pós-Graduação em Música da UFRJ, Rio de Janeiro, v. 23, n. 1, p. 67-91, 2010. Disponível em: https://revistas.ufrj.br/index.php/rbm/article/view/29355. Acesso em: 03 ago. 2021.

BOSI, Alfredo. Narrativa e resistência. Itinerários. Araraquara, SP, n. 10, p. 11- 27, 1996. Disponível em: https://periodicos.fclar.unesp.br/itinerarios/article/view/2577/2207; acesso em: 25 jan. 2021.

CULLER, Jonathan. Teoria literária: uma introdução. Trad. Sandra Vasconcelos. São Paulo: Beca Produções Culturais LTDA, 1999.

CHARTIER, Roger. Cultura popular: revisitando um conceito historiográfico. Trad. Aone-Marie Milon Oliveira. Estudos Históricos, v.8, n.16, Rio de Janeiro, 1995, p. 179-192.

COMPAGNON, A. O demônio da teoria. Trad. Cleonice Paes Barreto Mourão, Consuelo Fortes Santiago. 2. Ed. Belo Horizonte: Editora UFMG, 2010.

Literatura para quê?. Trad. Laura Taddei Brandini. Belo Horizonte: Editora

UFMG, 2009.

EVARISTO, Conceição. A gente combinou de não morrer. In: Olhos D’água. 1. ed. Rio de Janeiro: Pallas: Fundação Biblioteca Nacional, 2016. p. 99 - 110. 
FANON, Frantz. Pele negra, máscaras brancas. Salvador: EDUFBA, 2008.

GAMA, Luiz. Primeiras trovas de Getulino (1959). Disponível em: https://www.literaturabrasileira.ufsc. br/_documents/0006-00867.html; acesso em: 07 maio 2021.

LIPOVETSKY, G. SERROY, J. A cultura-mundo: resposta a uma sociedade desorientada. São Paulo: Companhia da Letras, 2011.

NASCIMENTO, Érica Peçanha do. Depois que os escritores da periferia entraram em cena. In: NASCIMENTO, Érica Peçanha do. É tudo nosso! Produção cultural na periferia paulistana. Tese, São Paulo: Universidade de São Paulo, 2011, p. 101-112. Disponível em:

https://www.teses.usp.br/teses/disponiveis/8/8134/tde-12112012- 092647/pt-br.php; acesso em: 20 ago. 2021.

NASCIMENTO, Jorge Luiz do. Violência policial, racismo e resistência: notas a partir da MPB. In: VERMES, Mônica; SODRÉ, Paulo Roberto; SALGUEIRO, Wilberth (orgs.). Entre literatura e música. Vitória, ES: EDUFES, 2019, p. 71-98.

NATHANAILIDIS, Andressa Zoi. Das fissuras sociais ao grito pela arte: o rap, a revolta e a política, nos trâmites de uma "nova canção". 2011. Anais do XXXIV Congresso Brasileiro de Ciências da Comunicação - Recife, PE - 2 a 6 set. 2011, p. 1-15, 2011. Disponível em: http://www.intercom.org.br/ papers/nacionais/2011/resumos/R6-2333- 1.pdf; acesso em: 20 ago. 2021.

PIGNATARI, Dante. Canto da Língua: Alberto Nepomuceno e a Invenção da Canção Brasileira. São Paulo: Editora da Universidade, 2015.

RIBEIRO, Cristina Betioli. Folclore e nacionalidade na literatura brasileira do século XIX. Tempo (online) (Revista do Departamento e Programa de PósGraduação em História da UFF), v.10, n.20, 2006, p.143-158.

RACIONAIS MC’S. Sobrevivendo no inferno. Casa Nostra/Zambia, ZA-050-1, 1997. 1 CDs.

ROCHA, Maristela. O batuque: da resistência à música de concerto. Um olhar sobre "Dança de Negros”, de Alberto Nepomuceno. NAVA. São João Del Rei, MG, v. 5, n. 1 e 2, p. 155 173, ago. 2019 e 2020. Disponível em: https://periodicos.uff.br/index.php/nava/article/view/32695/21948; acesso em: 19 abr. 2021.

SANTOS, Eduardo Antonio Estevam. Luiz Gama e a sátira racial como poesia de transgressão: poéticas diaspóricas como contranarrativa à ideia de raça. Almanack. Guarulhos, SP, n. 11, p. 707-748, dez. 2015. Disponível em: https://www.scielo.br/pdf/alm/n11/pt_2236-4633-alm-11-00707.pdf; acesso em: 20 ago. 2021. 